\title{
Electrochemical properties of nanoporous carbon electrodes*
}

\author{
E.Lust ${ }^{1,2}$, G.Nurk ${ }^{1,2}$, A.Jänes ${ }^{1,2}$, M.Arulepp ${ }^{1,2}$, \\ L.Permann ${ }^{2}$, P.Nigu ${ }^{2}$, P.Möller ${ }^{2}$ \\ 1 Institute of Physical Chemistry, University of Tartu \\ 2 Jakobi Str., 51014 Tartu, Estonia \\ 2 Tartu Technologies Ltd., 185 Riia Str., 51014 Tartu, Estonia
}

Received October 5, 2001, in final form December 28, 2001

\begin{abstract}
Electrical double layer and electrochemical characteristics at the nanoporous carbon $\left(\mathrm{C}_{2} \mathrm{H}_{5}\right)_{4} \mathrm{NBF}_{4}+$ acetonitrile interface have been studied by the cyclic voltammetry and impedance spectroscopy methods. The value of zero charge potential $\left(0.23 \mathrm{~V}\right.$ vs. SCE in $\left.\mathrm{H}_{2} \mathrm{O}\right)$, the region of ideal polarizability and other characteristics have been established. Analysis of com-

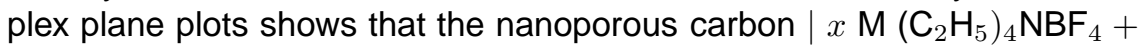
acetonitrile interface can be simulated by the equivalent circuit, in which the two parallel conduction parts in the solid and liquid phases are interconnected by the double layer capacitance in parallel with the complex admittance of hindered reaction of the charge transfer process. The values of the characteristic frequency depend on the electrolyte concentration and on the electrode potential, i.e. on the nature of ions adsorbed at the surface of nanoporous carbon electrode.
\end{abstract}

Key words: electrical double layer, nanoporous carbon, zero charge potential, nonaqueous electrolyte solution

PACS: 68.08.-p, 68.08.De

\section{Introduction and theoretical background}

Electrochemical and electrical double layer characteristics of the carbon electrodes have been studied for a long time, but there are many problems, which have not been solved at the moment. Electric double layer characteristics of various carbonaceous materials are very important as these parameters determine the electrical behaviour of the electrical double layer capacitors (EDLC-s).

EDLC-s are the energy conservation systems, in which the electrical charge is stored in the electric double layer and it is based mainly on the electrostatic interactions. As the electrostatic interactions are significantly less detrimental to electrodes

*This paper is dedicated to Jean-Pierre Badiali on the occasion of his 60th birthday 
and solution stability than the usual electrochemical redox reactions, used for the generation of electricity in the fuel cells as well as in various batteries, EDLC can be recharged-discharged up to $10^{6}$ times. The very important advantages of EDLC are their reversibility and comparatively low temperature coefficient [1]. However, a very important problem with EDLC is their relatively low energy density compared with the rechargeable batteries. It is well known that the performance specifications of electrochemical capacitor e.g. in terms of the relations between the achieved power densities and corresponding energy densities depend on the equivalent series resistance (ESR) and on the internal distribution of electrode resistance (IER) in the pore matrix of the electrodes.

The capacitance of EDLC depends mainly on the surface area of carbon material used for the preparation of the electrodes. Theoretically, the higher surface area of the activated carbon the higher specific capacitance should be expected. The specific capacitance should be defined as the specific surface area of carbon multiplied by the double layer capacitance $C_{\mathrm{dl}}\left(\mathrm{F} / \mathrm{cm}^{2}\right)$ [1]. However, the practical situation is more complicated and usually the capacitance measured does not have the linear relationship with the specific surface area of the electrode material. In fact, some activated carbons with smaller specific surface area demonstrate higher specific capacitance values than those with larger surface area. There are two main reasons for this phenomenon:

(1) the double layer capacitance $C_{\mathrm{dl}}$ varies with various types of activated carbons that were made from the different types of precursors (through different processes and subsequent treatments);

(2) the nanopores with small diameter may not be accessible to the electrolyte solution, simply because the electrolyte ions, especially big organic ions and ions with the hydration cell, are too big to enter into the nanopores. Thus, the surface area of these non-accessible nanopores will not contribute to the total double layer capacitance of the electrode material.

It should be noted that in the literature there are very big differences between the values of the electric double layer capacitance of the carbonaceous materials, ranging from $3 \mu \mathrm{F} / \mathrm{cm}^{2}$ for the basal plane $\mathrm{C}(0001)$ (cut surface) of stress-annealed highly oriented pyrolytic graphite (HOPC) to $70 \mu \mathrm{F} / \mathrm{cm}^{-2}$ for the polished graphite edge plane [1-3]. This surprisingly low non-faradaic differential capacitance value for the $\mathrm{C}(0001)$ plane compared with the capacitance values for metals $\left(18 \ldots 20 \mu \mathrm{F} / \mathrm{cm}^{2}\right.$ for $\mathrm{Hg}$, Bi and $\mathrm{Cd}$ ), having nearly parabolic dependence on the electrode potential, can be explained on the basis that the substantial fraction of the potential drop between the solid electrode and the solution occurs in a space charge layer within the HOPC. In $70^{\text {th }}$ and $80^{\text {th }}$, various physical models were introduced into the electrochemistry, taking into account the potential drop in the thin surface layer of the electrode.

The model worked out by Amokrane and Badiali [4,5] gives good explanations of the capacitance data established for different metal electrodes in various aqueous and non-aqueous solutions [6,7]. In this theory, the metal is described using the density functional formalism, and the metal-solvent interaction as a sum of an attractive 
term (due to the dispersion forces (Van der Waals)) and a repulsion term (simulating the exclusion of the metal electrons from the electron cloud of the solvent molecules).

According to the results of investigations [4-7], the inverse inner layer capacitance can be expressed as

$$
C_{\mathrm{i}}^{-1}=C_{\mathrm{s}}^{-1}+C_{\mathrm{m}}^{-1},
$$

where $C_{\mathrm{m}}$ is the capacitance of the metal phase. Systematic analysis of experimental data shows that the inverse capacitance of the solvent layer with a thickness $l$ can be obtained as

$$
C_{\mathrm{s}}^{-1}=4 \pi l-\left(4 \pi N_{\mathrm{s}} \mu^{2} / \varepsilon k T\right)\left\{1-\operatorname{coth}^{2}(x)+1 / x^{2}\right\},
$$

where $N_{\mathrm{s}}$ is the number of dipoles per unit area; $\mu$ is the value of dipole moment; $x=\mu E / k T$ ( $k$ is the Boltzmann constant) [4,5]. The effective field acting on a dipole was taken as $E=4 \pi \sigma^{*} / \varepsilon$, where $\varepsilon$ is an adjustable parameter having the meaning of an effective dielectric constant; and $\sigma^{*}$ is an effective charge density. The dependence of the capacitance of the carbon phase on the electrode rational potential $\left(E-E_{\sigma=0}\right.$, where $E_{\sigma=0}$ is the zero charge potential), obtained assuming, to a first approximation, that this simplified model developed in [4,5] is valid for $\mathrm{C}(0001)$ with the cut surface (prepared according to the method described in $[8,9]$ ) as well as for polished edge plane of HOPG and glassy carbon electrodes, is given in figure 1. It should be noted that the Amokrane and Badiali model has been worked out for the homogeneous planar and smooth surfaces with translational invariance parallel to the metal surface [4,5]. Therefore, the values of $C_{\mathrm{m}}$ obtained for the cut $\mathrm{C}(0001) \mid 0.1 \mathrm{M} \mathrm{NaF}+\mathrm{H}_{2} \mathrm{O}$ as well as for $\mathrm{C}(0001) \mid 0.2 \mathrm{M}\left(\mathrm{C}_{3} \mathrm{H}_{7}\right) \mathrm{NBF}_{4}+$ acetonitrile interface are realistic as the surface roughness of cut HOPC, i.e. $\mathrm{C}(0001)$ plane is very small $[8,9]$. The inner layer values used for the calculation of the values of $C_{\mathrm{m}}$ for other carbon (i.e. glassy carbon) electrodes have been calculated using the surface roughness factor obtained from impedance data according to the various models [1,10-17] (Parsons-Zobel plot method, Valette-Hamelin approach, fractal analysis described more in detail in $[12,16,17])$. According to the systematic analysis of experimental data, $[12,16]$, the inner layer capacitance values depend only slightly on the surface roughness of the solid electrode at $|E|>E_{\sigma=0}$, if $c_{\mathrm{el}} \geqslant 0.1 \mathrm{M}$. The values of inner layer capacitance obtained for polycrystalline metal electrodes lie between the $C_{\mathrm{i}}$ values for single crystal planes for the corresponding metal $[6,12,16]$, have the medium values and, to a first very rough approximation, characterize the inner layer parameters for metal | electrolyte interface under discussion. Only for dilute electrolyte systems $\left(c_{\mathrm{el}} \leqslant 0.01 \mathrm{M}\right)$ in the region of zero charge potential there is a complicated dependence of $C_{\mathrm{i}}$ on $E$, but at the electrode potentials $|E|>E_{\sigma=0}$, there is a monotonic dependence of $C_{\mathrm{i}}$ on $E$. More detailed analysis of the problems for polycrystalline metal electrode | electrolyte interface as well as for liquid | liquid interface are given in [10-17]. Thus, the values of $C_{\mathrm{m}}$ for glassy carbon electrodes in $0.1 \mathrm{M}$ electrolyte solution have to be taken with some reservation because the values of the inner layer capacitance depend somewhat on the surface roughness values used for the calculation of $C_{\mathrm{m}}$ values [6,7,10-12]. However, the order of $C_{\mathrm{m}}$ values seems to be reasonable and, thus, the data in figure 1 indicate that the capacitance of the 
carbon phase depends noticeably on the crystallographic structure of the carbon material [1-3]. For that reason it seems to us that in any case, the potential drop in the thin surface layer of carbonaceous material is very important, but additional studies are inevitable.

It should be noted that the carbonaceous materials show the frequency-dependent capacitance even though the capacitance should be independent of frequency. This abnormal frequency-dependence is called a distributed characteristic or "frequency dispersion" of the electrical properties [1]. A circuit element with the distributed characteristic can not be exactly expressed as a combination of a finite number of ideal circuit elements, except in certain limiting cases. The distributed characteristic results mainly from the two origins [1,6,18-25].

(1) It appears non-locally when a dimension of a system under study (electrode thickness or pore length) is longer than the characteristic length (for example, diffusion length or ac penetration depth), which is a function of frequency. This type of a distributed characteristic exists even when all system properties are homogeneous and space-invariant (double layer charging of a porous electrode, diffusion in diffusion-limited systems, adsorption of anions and cations, surface reconstruction and transformation in adlayers).

(2) The distributed characteristic is attributed to the various heterogeneities: geometric inhomogeneity, such as the surface roughness or the distribution of pore size as well as the crystallographic anisotropy and the surface disorder of a polycrystalline electrode.

Beginning essentially with the work of de Levie [20,22,23], a large number of various models have been developed $[1,18,19,21,24,25]$ to theoretically describe the experimental behaviour of the porous electrodes. A very important direction is the investigation of the influence of the pore geometry on the data of electrical impedance spectroscopy (EIS) [24,25]. Some authors used simple modifications of the classical Randles-Frumkin-Melik-Gaikazyan equivalent circuits, involving a constant phase element or Warburg diffusion impedance modified according to the boundary conditions $[1,21,26-30]$, as well as the branched transmission line equivalent circuits [1,18,31]. Paasch et al. [21] developed a theory for macroscopically homogeneous porous electrode, where the three main processes are considered: (a) ionic conductivity in the porous electrolyte and electronic conductance in the electrode (solid) phase; (b) charging the double layer at the solid | liquid interface; and (c) the simple charge transfer reaction (ctr.) at the interface. The averaged polarization at the porous surface was described by the diffusion equation with the linear source term representing the ctr. with the charge transfer resistance $R_{\mathrm{ctr}}$. This leads to the polarization of the porous electrode. According to this theory the position $(x)$ and time-dependent $(t)$ polarization $(\tilde{E}(x, t))$ (averaged for the porous surface) has been given (without regard to an unknown constant) as

$$
\tilde{E}(x, t) \equiv \phi_{1}-\phi_{2}
$$




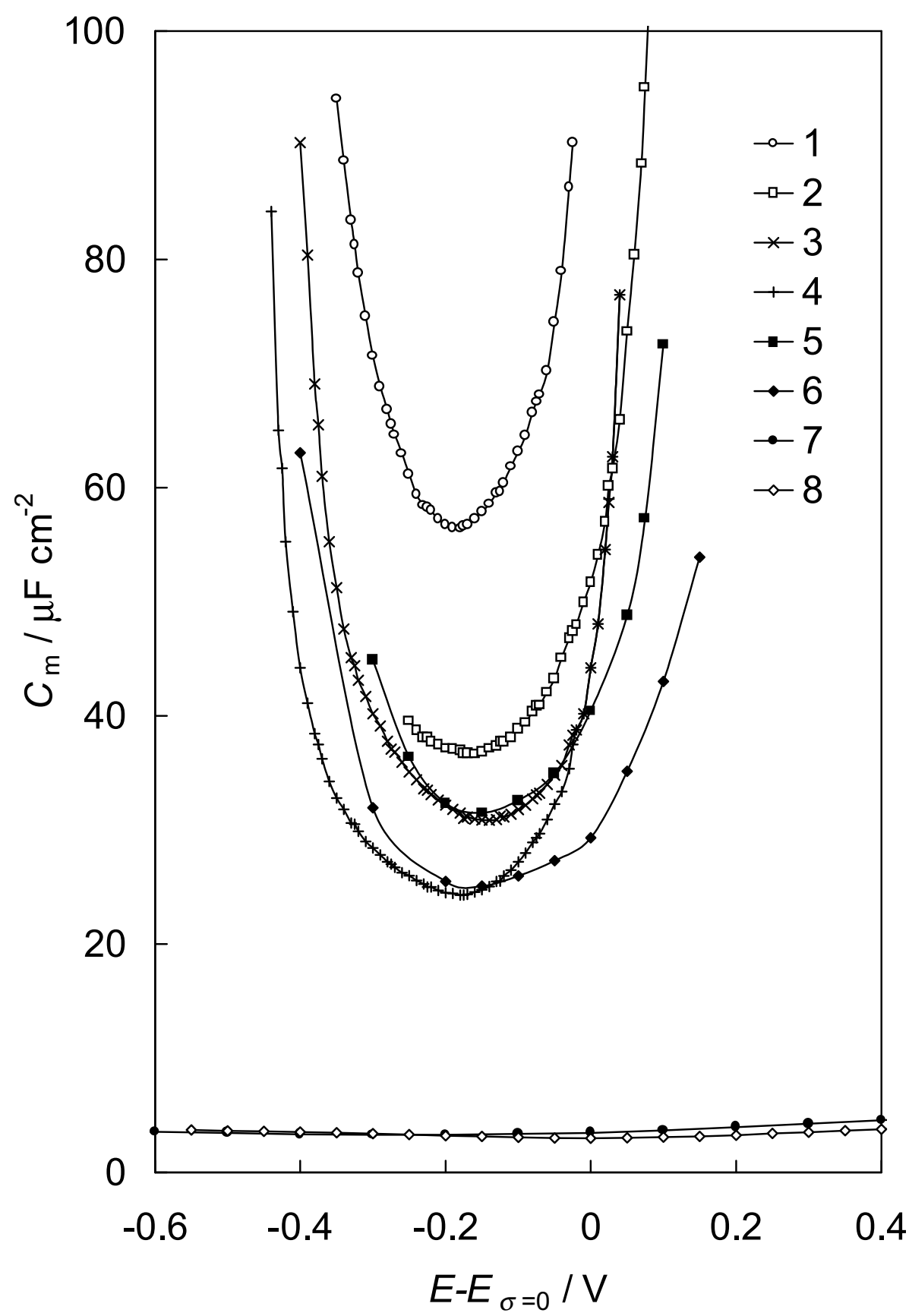

Figure 1. The dependence of the electrode phase capacitance on the rational electrode potential for various electrode materials: (1) - $\mathrm{Cd}(0001)$; (2) - Hg; (3) - $\operatorname{Bi}(111) ;(4)$ - $\mathrm{Sb}(111) ;(5,6)$ - glassy carbon; (7) - stress annealed pyrolytic graphite (recalc. from [1-3]); and (8) - stress annealed $\mathrm{C}(0001)$ (recalculated from data in [2]) in surface inactive electrolyte solutions $\left(0.1 \mathrm{M} \mathrm{NaF}+\mathrm{H}_{2} \mathrm{O}\right)(1-6,8)$ and in $0.2 \mathrm{M}\left(\mathrm{C}_{3} \mathrm{H}_{7}\right)_{4} \mathrm{NBF}_{4}+$ acetonitrile solution (7). 
where $\phi_{1}$ is a value of potential in the solid phase (taken independent of $x, \phi_{1} \neq f(x)$ ) [21]. The potential in the porous electrolyte $\phi_{2}$ depends on the conductivity, double layer formation parameters and ctr. characteristics of the interface. Averaging this potential over the volume element containing many pores gives the position- and time-dependent potential $\left(\phi_{2}(x, t)\right)$.

The electrochemical impedance of an interface is determined by the potential drop $E_{\text {el }}$ over an electrode [21]

$$
\begin{gathered}
E_{\mathrm{el}}(\omega)=\phi_{1, \mathrm{a}}(d, \omega)-\phi_{2, \mathrm{a}}(0, \omega)=E_{\mathrm{a}}(d, \omega)+\phi_{2, \mathrm{a}}(d, \omega)-\phi_{2, \mathrm{a}}(0, \omega), \\
Z(\omega)=E_{\mathrm{el}}(\omega) / A j_{\mathrm{a}},
\end{gathered}
$$

where $\phi_{1, \mathrm{a}}(d, \omega)$ is the solid phase potential at the contact side $(x=d) ; \phi_{2, \mathrm{a}}(0, \omega)$ is the electrolyte potential at electrolyte side $(x=0) ; \omega$ is the ac angular frequency; and $j_{a}$ is the amplitude of the current density (reported to unit geometrical area of the electrode); $A$ is the flat cross-section electrode area.

Using the conditions, which are usual in electrochemistry [19], the electrode impedance has been obtained as

$$
Z(\omega)=A^{-1}\left[\frac{\rho_{1}^{2}+\rho_{2}^{2}}{\rho_{1}+\rho_{2}} \frac{\operatorname{coth}(d \beta)}{\beta}+\frac{2 \rho_{1} \rho_{2}}{\rho_{1}+\rho_{2}} \frac{1}{\beta \sinh (d \beta)}+\frac{d \rho_{1} \rho_{2}}{\rho_{1}+\rho_{2}}\right]
$$

with

$$
\beta=\frac{1}{d}\left(\frac{k+\mathrm{i} \omega}{\omega_{1}}\right)^{1 / 2} \text { and } \omega_{1}=\frac{K}{d^{2}},
$$

where $\rho_{1}$ and $\rho_{2}$ are the resistivities per unit length of the electrode material and of the electrolyte in the pores, respectively [21,32]; $\omega_{1}$ is a characteristic frequency, related to the finite "field diffusion" [21]. Parameter $k$ is the characteristic frequency proportional to the ratio of the exchange current density $j_{o}$ to the double layer capacitance $C$; and $K$ is the so-called "field-diffusion constant", depending on the ohmic resistivities $\left(\rho_{1}\right.$ and $\left.\rho_{2}\right)$ and on the value of capacitance. The ac penetration length $\lambda$ is defined as [21]

$$
\lambda=\left(\frac{2 K / k}{\left(1+\omega^{2} / k^{2}\right)^{1 / 2}+1}\right)^{1 / 2} .
$$

In the conditions of diffusional hindrance at a planar porous electrode, the value of charge transfer resistance, $R_{\mathrm{ctr}}$, has to be replaced as follows [21]

$$
R_{\mathrm{ctr}} \rightarrow R_{\mathrm{ctr}} z(\omega)=R_{\mathrm{ctr}}\left(1+\sqrt{\omega_{2} / \mathrm{i} \omega}\right)
$$

where $z(\omega)=1 / y(\omega)$ is the value of volume-averaged hindrance impedance, describing the deviation of a porous system from the conditions of the real charge transfer resistance. For the simple electrochemical charge transfer reaction, the characteristic frequency is given as

$$
\omega_{2}=k_{\text {het }}^{2} / D
$$


where $D$ denotes the diffusion coefficient of the electroactive species and $k_{\text {het }}=k_{\text {ox }}+$ $k_{\text {red }}$ is a rate constant. For macroscopically homogeneous surfaces the equation (8) seems to explain the dominant dependence which only has to be corrected for the fact that the diffusion is finite owing to the small nanopore size. The corrected hindrance impedance for a single kind of diffusing species, when the boundary condition is not a transmissive one, will be of the form

$$
z(\omega)=1+\sqrt{\omega_{2} / \mathrm{i} \omega} \operatorname{coth}\left(\sqrt{\mathrm{i} \omega / \omega_{3}}\right)
$$

with

$$
\omega_{3}=D / l_{\mathrm{p}}^{2},
$$

where $l_{\mathrm{p}}$ denotes the characteristic pore dimension [19]. Compared with the case of a simple ctr, in the Paasch et al. model I, there are two additional parameters, $\omega_{2}$ and $\omega_{3}$, i.e. parameters characteristic of the porous electrodes if the finite diffusion takes place.

\section{Experimental}

\subsection{Electrode preparation and other experimental details}

The electrodes were constituted by an aluminium foil current collector and from the active material layer. The active material used (noted as ID711) consists of nanoporous carbon (prepared from TiC "stark" by the chlorination method according to the preparation scheme presented in [26-30]); of the mixture of binder (poly-tetra-fluoro-ethylene, PTFE, $60 \%$ solution in $\mathrm{H}_{2} \mathrm{O}$ "Aldrich") and of the carbon black ("Aldrich"). The carbon black was added to decrease the ohmic resistance of the electroactive material layer. This mixture was laminated on the Ni foil and pressed together to form a very flexible layer of the active electrode material. After drying and plating under the vacuum, this material was covered by the $\mathrm{Al}$ (99.9999\%) layer from one side [34-37]. After that the Al-covered carbon layer was spot-welded in the Ar atmosphere to the Al foil current collector. The limits of ideal polarizability of $\mathrm{Al}$ foil have been established by cyclic voltammetry as well as by impedance spectroscopy methods.

The electrolyte used was prepared from the acetonitrile (AN) $\left(0.003 \% \mathrm{H}_{2} \mathrm{O}\right.$; Riedel de Haen), stored over the molecular sieves before using, and from the $\left(\mathrm{C}_{2} \mathrm{H}_{5}\right)_{4} \mathrm{NBF}_{4}$ salt $\left(99.9 \% ; 0.005 \% \mathrm{H}_{2} \mathrm{O}\right.$; Pred Materials International, Inc.). The three electrode standard glass cell with the very big counter electrode (apparent area $\sim 30 \mathrm{~cm}^{2}$ ), prepared from the carbon cloth, was used. The reference electrode was an aqueous saturated calomel electrode $\left(\mathrm{SCE}\right.$ in $\mathrm{H}_{2} \mathrm{O}$ ) connected through the

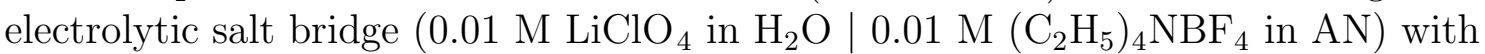
the measurement system [12]. Ar (99.9999 \%, AGA) was used for the saturation of solutions. Specific surface area $\left(S_{Q}\right)$, pore size distribution, micropore volume $\left(V_{\mathrm{m}}\right)$, micropore area $\left(S_{\mathrm{m}}\right)$ and other parameters were obtained using the Gemini 2375 (Micromeritics, Inc.) system and calculated according to the methods described in 
Table 1. Gas phase characteristics for nanostructured carbon ID711.

\begin{tabular}{ll}
\hline Parameter & Value \\
\hline BET surface area $/ \mathrm{m}^{2} \mathrm{~g}^{-1}$ & $950 \pm 30$ \\
Nano(micro)pore area $/ \mathrm{m}^{2} \mathrm{~g}^{-1}$ & $660 \pm 20$ \\
External surface area $/ \mathrm{m}^{2} \mathrm{~g}^{-1}$ & $285 \pm 15$ \\
Micropore volume $/ \mathrm{cm}^{3} \mathrm{~g}^{-1}$ & $0.49 \pm 0.03$ \\
Adsorption average pore diameter (calculated according & \\
to [38]) $/ \AA$ & $22 \pm 1$ \\
\hline
\end{tabular}

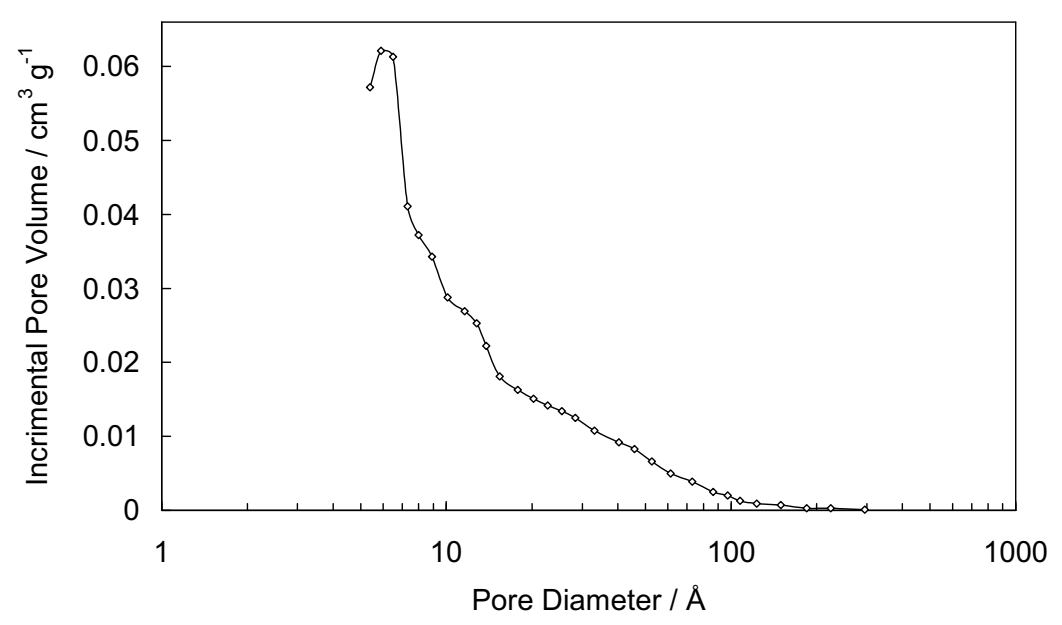

Figure 2. Pore size distribution for nanosctructured carbon ID711.

[38]. Some more important characteristics obtained are given in table 1 and in figure 2. For the determination of the precision of the experimental data, statistical treatment of the BET and impedance data was carried out. A total numbers of independent experiments $n \geqslant 10$ for BET analysis (10 different samples) and $n \geqslant 3$ for impedance analysis (three different electrodes) were used. The results of BET analysis are given in table 1 . The ac measurements (for one sample averaged over 10 cycles) were carried out at the amplitude of $5 \mathrm{mV}$ (rms) in the frequency range from $100 \mathrm{kHz}$ to $1 \mathrm{mHz}$ and at fixed electrode potentials. The values of mean capacitance, total impedance and resistance have been established. It was found that the experimental values of series differential capacitance and resistance can be established with the relative error smaller than $6 \%$ for the whole potential region of ideal polarizability of the electrode. In the region of zero charge potential $E_{\sigma=0}$, the relative error is smaller than $4 \%$ in the concentrated electrolyte solutions (1.5 M and 0.1 M). For the less concentrated solutions, the relative error in differential capacitance is somewhat higher, but smaller than $7 \%$. For the more correct statistical analysis of impedance data, the large number of independent experiments is inevitable and the results of systematic analysis will be published soon. 


\subsection{Cyclic voltammetry $(j, E-)$ curves}

The cyclic voltammetry curves for $x \mathrm{M}\left(\mathrm{C}_{2} \mathrm{H}_{5}\right)_{4} \mathrm{NBF}_{4}$ acetonitrile solution $(0.005<x<1.5)$, obtained at small scan rates of potential $v=\mathrm{d} E / \mathrm{d} t \leqslant 5 \mathrm{mV} / \mathrm{s}$, presented in figure 3, have a nearly rectangular form and a mirror image symmetry of the current responses about the zero current line. Accordingly, the porous carbon electrodes are ideally polarizable in the region of potentials from -1.4 to $1.4 \mathrm{~V}$ (vs. $\mathrm{SCE}$ in $\mathrm{H}_{2} \mathrm{O}$ ). The experimental data show that the shape of $j, E$-curves is independent of the number of current cycle, $n$, if $n \geqslant 5$. Thus, the nanoporous carbon electrodes demonstrate the stable electrochemical properties in this region of potentials. i.e. in the region of ideal polarizability. At $c_{\mathrm{el}}=$ const, the current responses increase almost the expected way with large $\nu$ values (figure $3 \mathrm{a}$ ), but with increasing $v \geqslant 20 \mathrm{mV} / \mathrm{s}\left(1.5 \mathrm{M}\left(\mathrm{C}_{2} \mathrm{H}_{5}\right)_{4} \mathrm{NBF}_{4}\right.$ in acetonitrile) the cyclic voltammograms become distorted from the rectangular form expected for an ideal capacitor material having a constant capacitance $[1,39]$. The data for more dilute solutions, presented in figures $3 \mathrm{~b}$ and $3 \mathrm{c}$, demonstrate that the shape of $j, E$-curves is independent of the potential scan rate if $v \leqslant 5 \mathrm{mV} / \mathrm{s}$ for $c_{\mathrm{el}} \leqslant 0.1 \mathrm{M}$ and $v \leqslant 2 \mathrm{mV} / \mathrm{s}$ for $c_{\mathrm{el}} \leqslant 5 \cdot 10^{-3} \mathrm{M}$. At higher scan rates there are very well expressed distortion effects in the $j, E$-curves, caused by the higher internal resistance of the system compared with the $1.5 \mathrm{M}$ solution, as well as by the onset of the so-called "electrolyte starvation" effect, referred to earlier by Conway et al. $[1,39]$ associated with the withdrawal of the electrolyte ions from the pore bulk electrolyte due to the adsorption of ions on the double layer interphases when they become charged. Thus, the scan rate at which the deviation of $j, E$-curves from the ideal behaviour starts, decreases with the dilution of the electrolyte solution. Additionally it should be noted that the establishment of the adsorption equilibrium in the nanopores is a very slow process, caused by the very small "effective" diffusion coefficient values of ions in nanopores, discussed more in detail later.

Comparison of data for $1.5 \mathrm{M}$ and $0.1 \mathrm{M}$ electrolyte solutions, obtained at small scan rates, shows that in the region of potentials $-0.1 \leqslant E \leqslant 0.5 \mathrm{~V}$ (SCE), there is a minimum of current density for $0.1 \mathrm{M}\left(\mathrm{C}_{2} \mathrm{H}_{5}\right)_{4} \mathrm{NBF}_{4}$ solution, in the case of metal electrodes explained by the diffuse nature of the electric double layer in the region of total (or free) zero charge $[1,6,12]$. Noticeably better-expressed current minima have been established for the $0.01 \mathrm{M}$ and $0.005 \mathrm{M} \mathrm{TEABF}_{4}+\mathrm{AN}$ solutions (figure $3 \mathrm{c}$ ). The current density at $\nu=$ const and $E=E_{\text {min }}$ decreases with the dilution of electrolyte (figure 4). Thus, this minimum is probably caused by the zero charge potential (or by the zero total charge potential) of porous carbon electrode. The potential of this minimum (figure 5) is practically independent of the direction of potential scan if $v \leqslant 1 \mathrm{mV} / \mathrm{s}$, as well as of the electrolyte concentration if $c_{\mathrm{el}} \leqslant 0.01 \mathrm{M}$.

The values of differential capacitance, corresponding mainly to the double layer capacitance, can be obtained as

$$
C=j v^{-1}=j(\mathrm{~d} E / \mathrm{d} t)^{-1} .
$$

The data in figure $6 \mathrm{a}$, obtained from $j, E$-curves, indicate that for $1.5 \mathrm{M}$ $\left(\mathrm{C}_{2} \mathrm{H}_{5}\right)_{4} \mathrm{NBF}_{4}+\mathrm{AN}$ solution in the limited region of electrode potential the ca- 


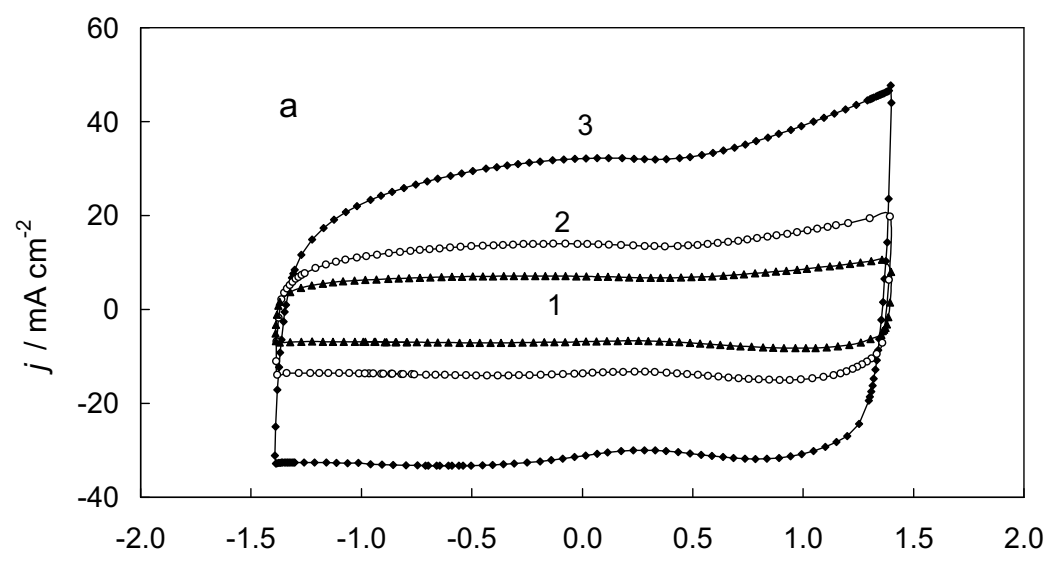

E / V vs. SCE
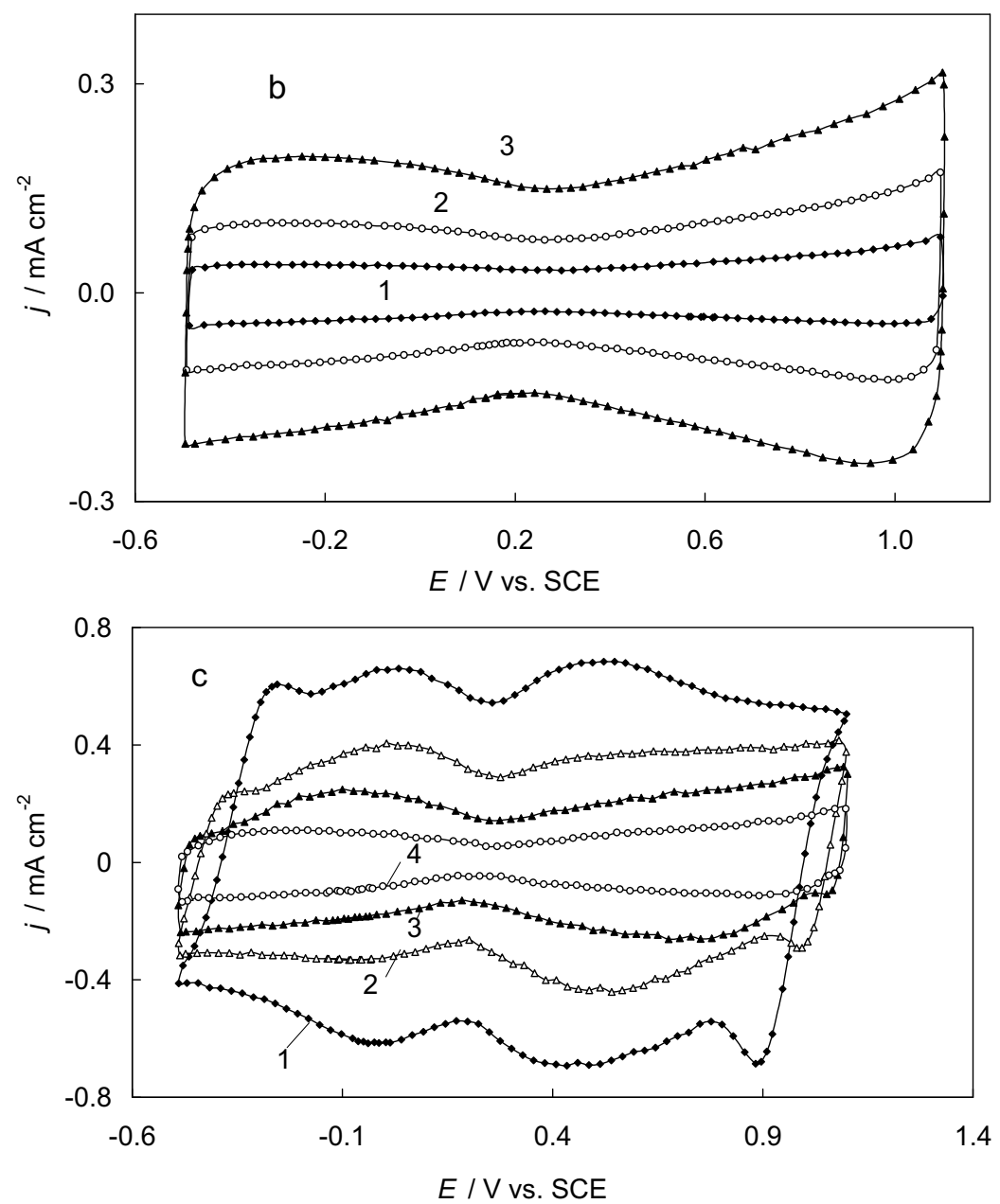

Figure 3. Current density vs. potential curves for nanostructured carbon ID711 in $1.5 \mathrm{M}(\mathrm{a}) ; 0.1 \mathrm{M}(\mathrm{b})$; and $0.005 \mathrm{M}(\mathrm{c})\left(\mathrm{C}_{2} \mathrm{H}_{5}\right)_{4} \mathrm{NBF}_{4}+$ acetonitrile solution at various potential scan rates: (a) (1) - 10, (2) - 20, (3) - 50; (b) (1) - 0.2, (2) $0.5,(3)-1.0$; and (c) (1) $-0.2,(2)-0.5,(3)-1.0,(4)-2.0 \mathrm{mV} / \mathrm{s}$. 


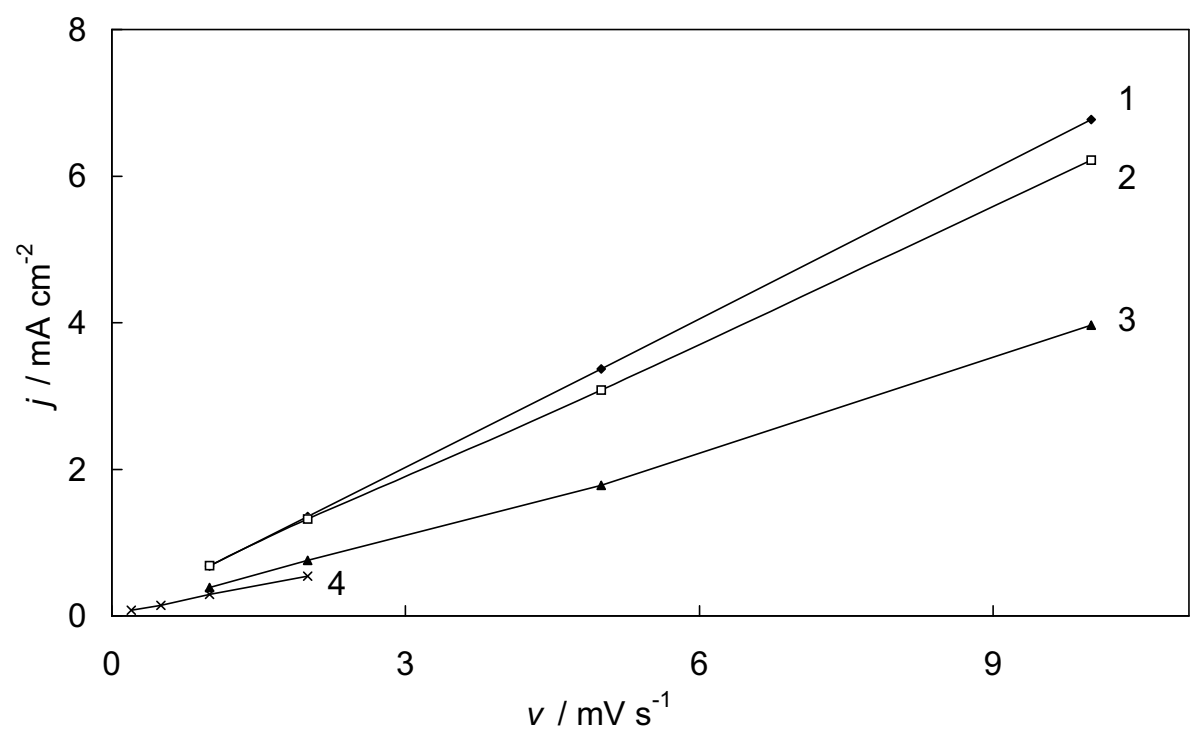

Figure 4. Current density vs. potential scan rate curves at $\mathrm{E}_{\min }$ for nanostructured carbon ID711 in $1.5 \mathrm{M}$ (1); $0.1 \mathrm{M}$ (2); $0.01 \mathrm{M}$ (3); and $0.005 \mathrm{M}$ $\left(\mathrm{C}_{2} \mathrm{H}_{5}\right)_{4} \mathrm{NBF}_{4}+$ acetonitrile solution.

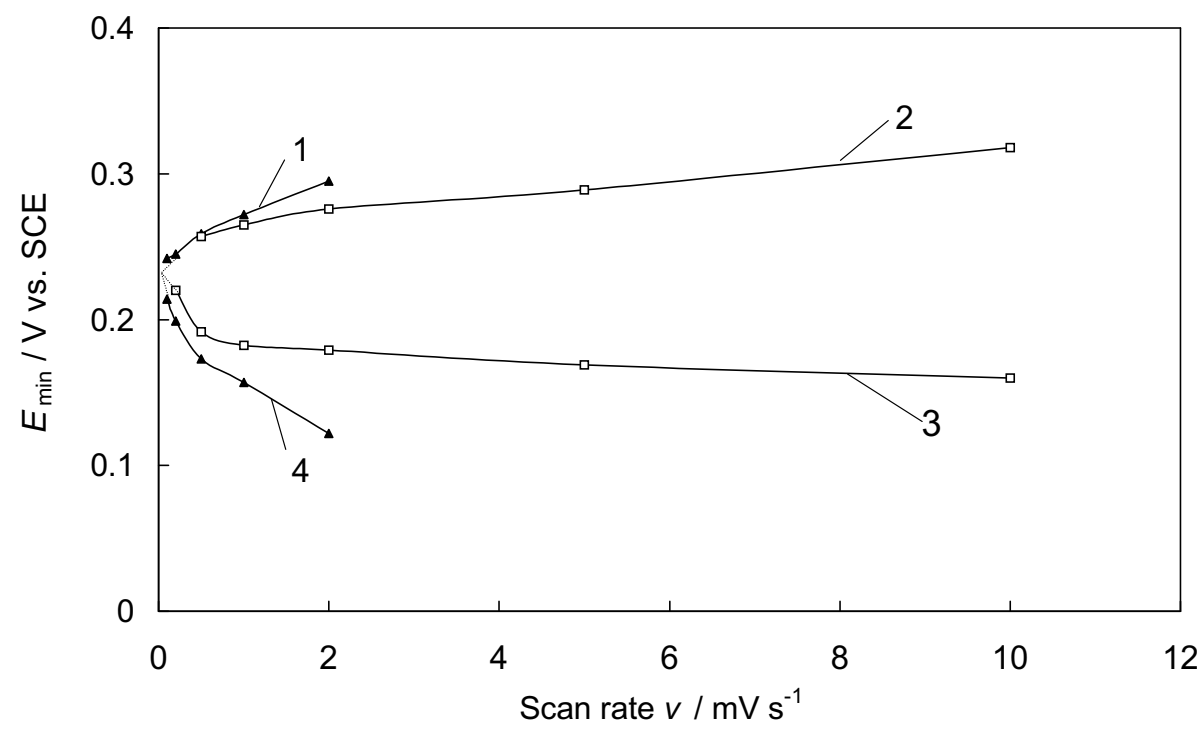

Figure 5. $\mathrm{E}_{\min }$ vs. potential scan rate curves for nanostructured ID711 carbon in $0.01 \mathrm{M}(1,4)$ and $0.1 \mathrm{M}(2,3)\left(\mathrm{C}_{2} \mathrm{H}_{5}\right)_{4} \mathrm{NBF}_{4}+$ acetonitrile solutions, obtained from $j, E$-curves with positive $(1,2)$ and negative $(3,4)$ direction of potential scan. 
pacitance, $C$, is practically independent of $v$ only at the values of $v \leqslant 20 \mathrm{mV} / \mathrm{s}$. It should be noted that the values of $C$ established from $j, E$-curves at $\nu \leqslant 10 \mathrm{mV} / \mathrm{s}$ are in good agreement with the $C_{\mathrm{s}}, E$-curves (figure $6 \mathrm{~b}$ ) (where $C_{\mathrm{s}}$ is the series capacitance, calculated from the complex plane $\left(Z^{\prime \prime}, Z^{\prime}\right)$ plots), measured at ac frequencies $f \leqslant 10 \mathrm{mHz}$. According to the experimental data, the series differential capacitance is independent of $f$ only at $f \leqslant 0.01 \mathrm{~Hz}$. At higher frequencies, there is a very big dependence of $C_{\mathrm{s}}$ on $f$, caused by the small values of ac penetration depth (equation (7)) compared with the pore length. The same is valid for the more dilute solutions (figure 7 ), but, in the region of capacitance minimum, there is a very weak dependence of $C_{\mathrm{s}}$ on $f$, as well as of $C$ on $\nu$, demonstrating that the almost equilibrium capacitance values have been established in the region of zero charge potential. At $|E|>E_{\sigma=0}$, there is a noticeable dependence of $C_{\mathrm{s}}$ on $f$ and $C$ on $\nu$. Thus, only at very small potential scan rates $(v \leqslant 10 \mathrm{mV} / \mathrm{s}$ the "equilibrium" values of capacitance and thus the maximal values of energy can be stored. The data in figure 7 show that at $E \sim 0.23 \mathrm{~V}$ (vs. SCE in $\mathrm{H}_{2} \mathrm{O}$ ) the very well expressed capacitance minimum (with the potential of the minimum $E_{\min }$ ) in $C, E$-curves has been observed. The series capacitance at $E_{\min }, C_{s, \min }$, decreases approximately linearly with $c^{1 / 2}$ (figure $7 \mathrm{c}$ ).

At higher scan rates, the value of $E_{\text {min }}$ depends on the direction of potential scan (figure $7 \mathrm{~d}$ ), which is caused by the very slow processes of adsorption-desorption and diffusion of ions in the nanopores. With the decrease of $v$ lower than $1 \mathrm{mV} / \mathrm{s}$, the difference between the $E_{\min }$ values for positive and negative going potential scans decreases (figure 4 ) and the $E_{\min }$ value, corresponding to the zero charge potential of nanoporous carbon electrode, can be taken equal to $0.23 \mathrm{~V}$ vs. SCE. However, it should be noted that for a more detailed analysis of the physical nature of the minimum in the $C, E$-curves, the future experimental investigations in more dilute electrolyte solutions as well as in conditions $v<0.5 \mathrm{mV} / \mathrm{s}$ are inevitable.

\subsection{Analysis of impedance data}

The $Z^{\prime \prime}, Z^{\prime}$-plots (so-called Nyquist plots, figure 8) were measured for 1.5 and $0.1 \mathrm{M}\left(\mathrm{C}_{2} \mathrm{H}_{5}\right)_{4} \mathrm{NBF}_{4}+\mathrm{AN}$ solutions in the range of ac frequency from $1 \cdot 10^{-3}$ to $1 \cdot 10^{5} \mathrm{~Hz}$ and in the region of potentials from -1.4 to $1.4 \mathrm{~V}$ (vs. SCE in $\mathrm{H}_{2} \mathrm{O}$ ) at fixed $E=$ const. The results obtained demonstrate that the shape of $Z^{\prime \prime}, Z^{\prime}$-plots noticeably depends on $c_{\mathrm{el}}$ as well as somewhat on the electrode potential. The $Z^{\prime \prime}, Z^{\prime}$ plots (at $f=$ const) were used for the calculation of the values of differential series capacitance $\left(C_{\mathrm{s}}\right.$, series circuit) and parallel capacitance $\left(C_{\mathrm{p}}\right.$, parallel circuit) values as well as of the series resistance $R_{\mathrm{s}}$ and parallel resistance $R_{\mathrm{p}}$ values. According to the data in figure $9 \mathrm{a}$, the $C_{\mathrm{s}}$ and $C_{\mathrm{p}}$ values level off to the limiting value of $C_{\mathrm{s}}(\omega \rightarrow 0)$ at $f \leqslant 5 \cdot 10^{-2} \mathrm{~Hz}$, indicating that the diffusion is a limiting stage of the adsorption process.

At $-1.4 \leqslant E \leqslant-0.7 \mathrm{~V}$ (SCE), the values of $C_{\mathrm{s}}(\omega=0)$ are somewhat higher for less concentrated electrolyte solutions, indicating that the limiting Gibbs adsorption values have been established for $\left(\mathrm{C}_{2} \mathrm{H}_{5}\right)_{4} \mathrm{~N}^{+}$cations at $c \geqslant 0.1 \mathrm{M}$. The inflection frequency for $C_{\mathrm{s}}, f$ - and $C_{\mathrm{p}}, f$-plots is somewhat higher for the more concentrated 

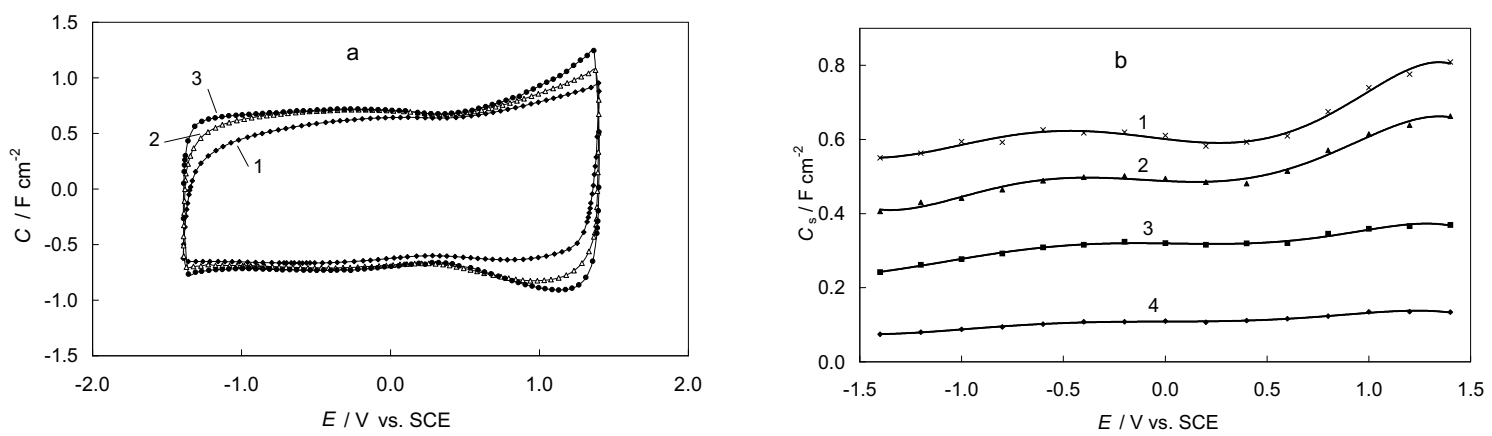

Figure 6. (a) $C, E$-curves for nanostructured carbon ID711 $\mid \begin{array}{lll}1.5 & \mathrm{M}\end{array}$ $\left(\mathrm{C}_{2} \mathrm{H}_{5}\right)_{4} \mathrm{NBF}_{4}+$ acetonitrile interface, calculated from $j, E$-curves at potential scan rates: $(1)-50 ;(2)-10$; and $(3)-2 \mathrm{mV} / \mathrm{s}$. (b) $C_{\mathrm{s}}, E$-curves the same interface at different ac frequencies: $(1)-0.01 ;(2)-0.1 ;(3)-1.0$; and $(4)-10 \mathrm{~Hz}$.
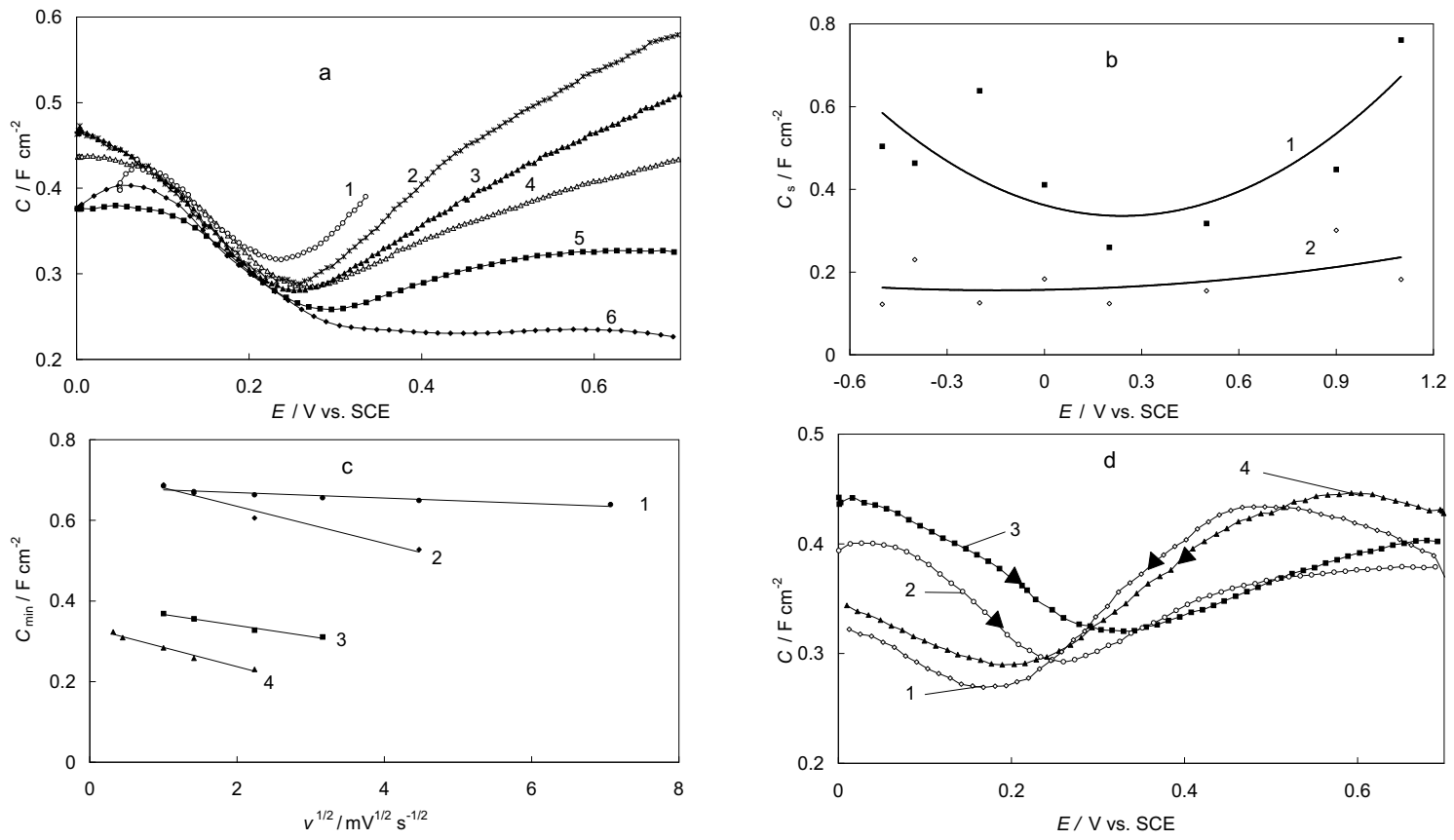

Figure 7. (a) $C, E$-curves for nanostructured carbon ID711 $\mid \begin{array}{lll}0.01 & \mathrm{M}\end{array}$ $\left(\mathrm{C}_{2} \mathrm{H}_{5}\right)_{4} \mathrm{NBF}_{4}+$ acetonitrile interface obtained from $j, E$ curves at different scan rates: $(1)-0.1 ;(2)-0.2 ;(3)-0.5 ;(4)-1 ;(5)-2$; and $(6)-5 \mathrm{mV} / \mathrm{s}$ (positive direction of potential scan). (b) $C_{\mathrm{s}}, E$ - curves for the same interface obtained from $Z^{\prime}, Z^{\prime \prime}$ curves at different ac frequencies: $(1)-0.01 ;(2)-0.1 \mathrm{~Hz}$. (c) $C_{\min }, \nu^{1 / 2}$ dependences for nanostructured carbon ID711 in (1) - $1.5 \mathrm{M}$; (2) - $0.1 \mathrm{M}$; (3) $0.01 \mathrm{M}$; and (4) - $0.005 \mathrm{M}\left(\mathrm{C}_{2} \mathrm{H}_{5}\right)_{4} \mathrm{NBF}_{4}+$ acetonitrile solutions. (d) $C, E$-curves for $0.005 \mathrm{M}(1,2)$ and $0.07 \mathrm{M}(3 ; 4)\left(\mathrm{C}_{2} \mathrm{H}_{5}\right)_{4} \mathrm{NBF}_{4}+$ acetonitrile solutions obtained from $j, E$-curves at potential scan rate $\nu=10 \mathrm{mV} / \mathrm{s}((1,4)$ - negative and $(2,3)$ - positive direction of potential scan). 

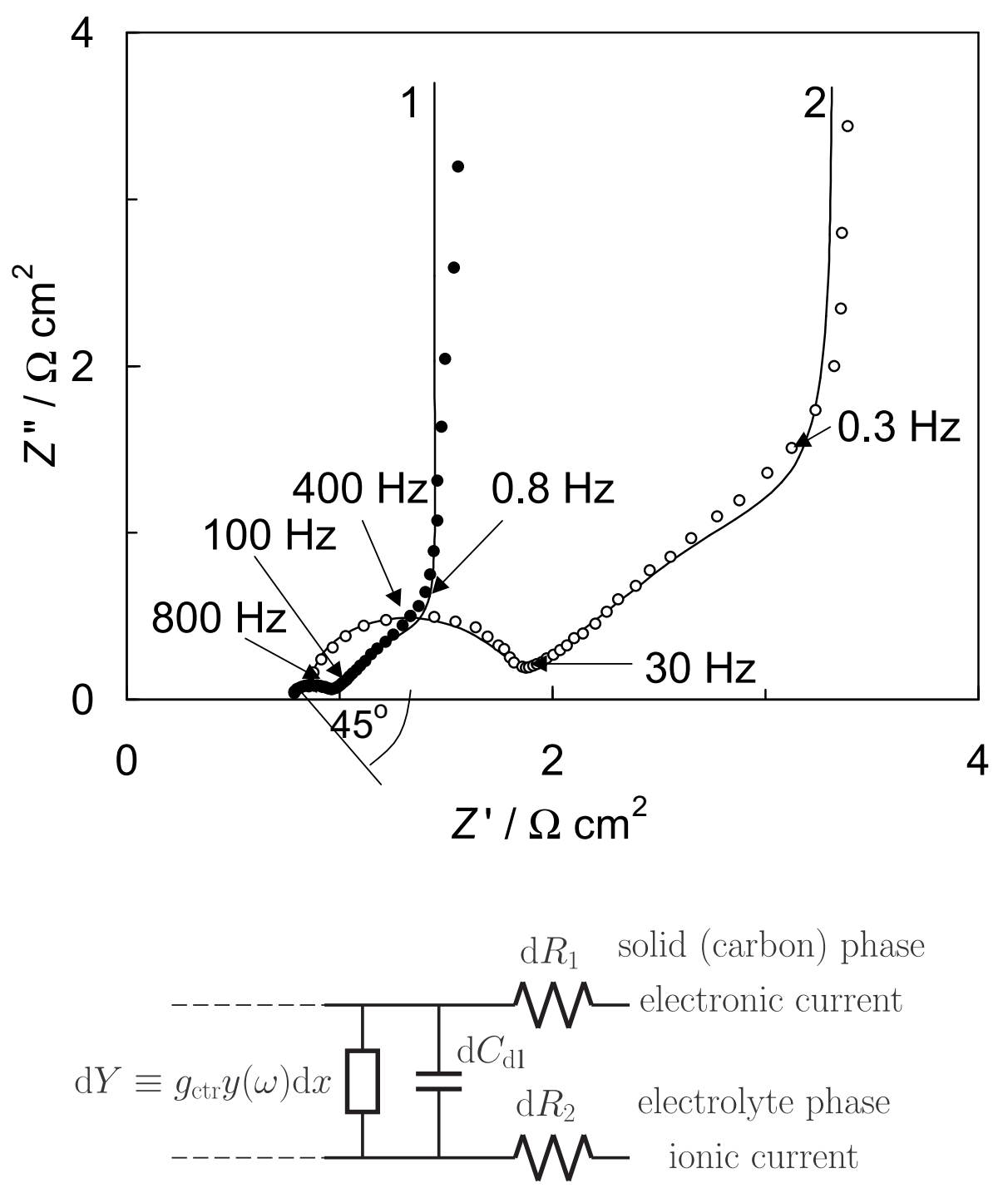

Figure 8. Complex plane plots for nanostructured carbon ID711 in 1.5 M (1) and $0.1 \mathrm{M}(2)\left(\mathrm{C}_{2} \mathrm{H}_{5}\right)_{4} \mathrm{NBF}_{4}+$ acetonitrile solutions at $E=1.0 \mathrm{~V}$ vs. SCE. Marks experimental data; and solid lines - data calculated according to the transmission line equivalent circuit (i.e. according to Paasch et al. model No. $1[21,42]$ ), where $\mathrm{d} Y$ is the complex admittance of the hindered charge transfer reaction (involving the hindrance factor $y(\omega)$ of the charge transfer reaction with the charge transfer conductance $\left.g_{\mathrm{ct}}\right) ; \mathrm{d} C_{d l}$ is the double layer capacitance; $\mathrm{d} R_{1}$ and $\mathrm{d} R_{2}$ are the ohmic resistance of the porous electrode material and of the electrolyte in the pore, respectively, in the volume element $A \mathrm{~d} x$. 

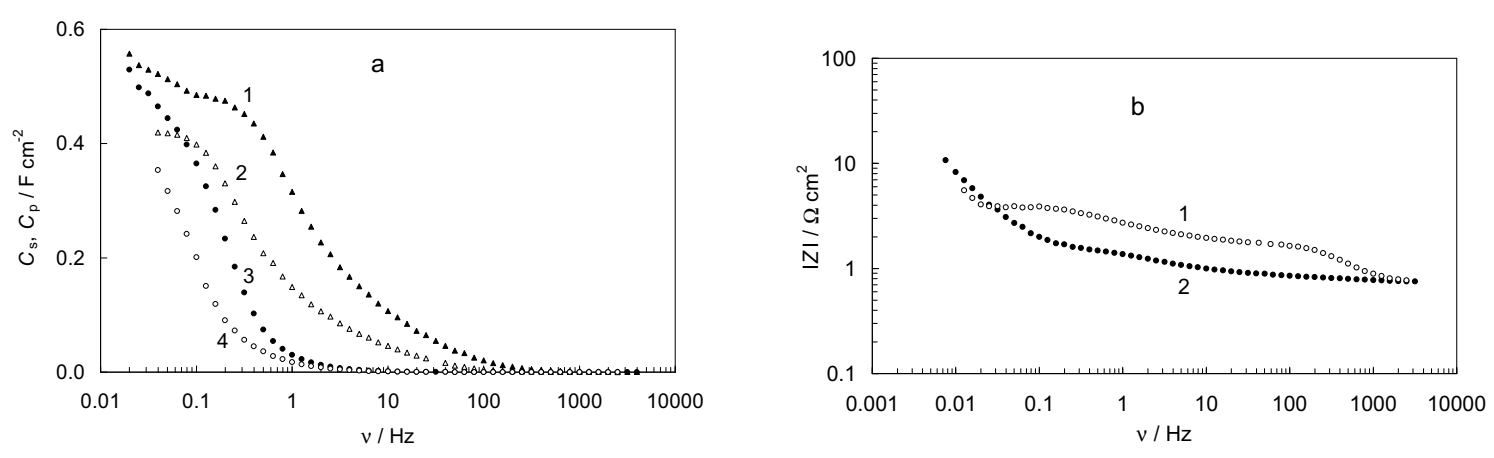

Figure 9. (a) $C_{\mathrm{s}}, \nu$-curves $(1,2)$ and $C_{\mathrm{p}}, \nu$-curves $(3,4)$ for nanostructured carbon ID711 in $1.5 \mathrm{M}(1,3)$ and $0.1 \mathrm{M}(2,4)\left(\mathrm{C}_{2} \mathrm{H}_{5}\right)_{4} \mathrm{NBF}_{4}+$ acetonitrile solutions at $E=0.2 \mathrm{~V}$ vs. SCE. (b) Bode plots for nanostructured carbon ID711 in $0.1 \mathrm{M}$ (1) and $1.5 \mathrm{M}(2)\left(\mathrm{C}_{2} \mathrm{H}_{5}\right)_{4} \mathrm{NBF}_{4}+$ acetonitrile solutions at $E=-1.2 \mathrm{~V}$ vs. SCE.

electrolyte solution, which is caused by the decrease of the influence of the diffuse layer effect, i.e. by the decrease of the Debye screening length with the increase of $c_{\mathrm{el}}[1,12,40]$. At low frequency, the $R_{\mathrm{s}}$ and $R_{\mathrm{p}}$ values are lower for less concentrated electrolyte solutions, which can be explained by the less compact structure of the adsorption layer of $\left(\mathrm{C}_{2} \mathrm{H}_{5}\right)_{4} \mathrm{~N}^{+}$ions in the pure capacitance region. At $E>0.7 \mathrm{~V}$, the $C_{\mathrm{s}}(\omega \rightarrow 0)$ values for more concentrated electrolyte solution are higher than those for less concentrated electrolyte, indicating that the value of limiting Gibbs adsorption $\Gamma_{\max }$ has not been established for $c \leqslant 1.5 \mathrm{M}\left(\mathrm{C}_{2} \mathrm{H}_{5}\right)_{4} \mathrm{NBF}_{4}+\mathrm{AN}$ solution if the weak specific adsorption of $\mathrm{BF}_{4}^{-}$anions takes place on nanoporous carbon.

Comparison of $C_{\mathrm{s}}$ values, obtained from impedance data and from $j, E$-curves, demonstrates a good agreement between the differential capacitance values of both series if $f \leqslant 10^{-1} \mathrm{~Hz}$ and $v \leqslant 1 \mathrm{mV} / \mathrm{s}$. Figure $9 \mathrm{~b}$ demonstrates the Bode $(|Z|, \log \omega)$ plots obtained at different electrode potentials $E=$ const and electrolyte concentrations. According to these data, the shape of $|Z|, \log \omega$-plots depends on the electrolyte concentration at ac frequency $5 \cdot 10^{-2}<f<5 \cdot 10^{2} \mathrm{~Hz}$. The higher values of $|Z|$ for $0.1 \mathrm{M}$ solution are caused mainly by the higher pore resistance values (discussed more in detail later). At $f \leqslant 1 \cdot 10^{-2} \mathrm{~Hz}$, there is no dependence of $|Z|$ on the electrolyte concentration, and $|Z|, \log \omega$-plots have a slope $\sim-45^{\circ}$, which is characteristic of the kinetically mixed process, i.e. of the process limited by the slow diffusion and the charge transfer stages (simulated by the equivalent circuit where the Warburg diffusion impedance and the charge transfer resistance are connected in series in the equivalent circuit). The dependence of the phase angle $\delta$ on $\log \omega$ is in very good agreement with the data in figure $9 \mathrm{~b}$.

\subsection{Analysis of complex plane plots}

The complex plane plots, measured for porous carbon $\left.\mid\left(\mathrm{C}_{2} \mathrm{H}_{5}\right)_{4} \mathrm{NBF}_{4}\right)+\mathrm{AN}$ interface at $E=$ const (figure 8), can be divided into the four main sections. At a high ac penetrability (at very low ac frequency $f \leqslant 1 \cdot 10^{-1} \mathrm{~Hz}$ ) the nanoporous carbon electrode behaves like a planar electrode since the penetration depth $\lambda$ (equation (7)) 
Table 2. Electrochemical characteristics nanoporous carbon ID $711 \mid x \quad \mathrm{M}$ $\left(\mathrm{C}_{2} \mathrm{H}_{5}\right)_{4} \mathrm{NBF}_{4}+$ acetonitrile interface.

\begin{tabular}{|l|cccc|cccc|}
\hline & \multicolumn{3}{|c|}{$1.5 \mathrm{M}\left(\mathrm{C}_{2} \mathrm{H}_{5}\right)_{4} \mathrm{NBF}_{4}$} & \multicolumn{4}{|c|}{$0.1 \mathrm{M}\left(\mathrm{C}_{2} \mathrm{H}_{5}\right)_{4} \mathrm{NBF}_{4}$} \\
$E / V$ vs. SCE & +1.2 & +0.2 & 0 & -1.2 & +1.2 & +0.2 & 0 & -1.2 \\
\hline$R_{\mathrm{el}} / \Omega \mathrm{cm}^{-2}$ & 0.77 & 0.94 & 0.95 & 0.75 & 0.84 & 0.88 & 0.89 & 0.76 \\
\hline$\alpha$ & 0.91 & 0.92 & 0.91 & 0.87 & 0.96 & 0.96 & 0.99 & 0.97 \\
\hline$v_{\text {pore }}$ & 0.207 & 0.241 & 0.241 & 0.200 & 0.224 & 0.168 & 0.166 & 0.153 \\
\hline $\mathrm{S}_{\mathrm{p}} / \mathrm{m}^{2} \mathrm{~cm}^{-3}$ & 70.8 & 103.7 & 103.8 & 54.3 & 86.5 & 80.6 & 74.3 & 64.7 \\
\hline $\mathrm{S}_{\mathrm{c}} / \mathrm{m}^{2} \mathrm{~g}^{-1}$ & 81.6 & 119.5 & 119.6 & 62.6 & 99.7 & 92.9 & 85.6 & 74.6 \\
\hline$R_{\text {pore }} / \Omega \mathrm{cm}^{-2}$ & 0.50 & 0.43 & 0.43 & 0.51 & 1.28 & 1.72 & 1.74 & 1.88 \\
\hline
\end{tabular}

$R_{\mathrm{el}}$ - total resistance of system at ac frequency $\nu \rightarrow \infty$,

$\alpha$ - constant phase exponent obtained at ac frequency $\nu \rightarrow 0$,

$v_{\text {pore }}$ - effective relative pore volume,

$S_{\mathrm{p}}-$ effective area per unit volume,

$S_{\mathrm{c}}$ - effective area per gram,

$R_{\text {pore }}$ - pore resistance.

is larger than the length of the pore so that an ac signal detects a large amount of the pore volume. In this region of the $Z^{\prime \prime}, Z^{\prime}$-plots (called the planar section [1]) the phase angle approaches asymptotically to $-85 \ldots-90$ degrees. However, according to the data in figure 8, the impedance (as well as the phase angle) at low ac frequency, i.e. at high $\lambda$ values shows non-ideal constant phase element (CPE) behaviour. The constant phase exponent values $\alpha$ less than 1.0 have been established: $\alpha \sim 0.90$ for $1.5 \mathrm{M}$ and $\alpha \sim 0.98$ for $0.1 \mathrm{M}$ solution $(\alpha=1$ for the planar ideally smooth electrode) (table 2). The values of $\alpha$ depend somewhat on the electrode potential (as well as on the electrolyte concentration), indicating that a weak specific adsorption of ions at different $E$ values is possible. The dependence of $\alpha$ on $c_{\mathrm{el}}$ as well as on $|E|$ indicates that the effectively working surface area of the electrode increases with the increase of the electrolyte concentration as well as of the surface charge density $[1,6,10-12,16,40]$. The increase of $\alpha$ can be explained by the increase of the effective Debye screening length with the dilution of solution $[1,11,40]$. Comparison of the values of the surface area, obtained according to the $\mathrm{N}_{2}$ adsorption data (BET), with the values of the effective surface area $S_{\mathrm{C}}$, obtained from the impedance data (tables 1 and 2), indicates that the very small nanopores are probably not accessible for the electrolyte ions. According to the model developed in [41], the deviation of $\alpha$ from unity is caused mainly by the pore size distribution in the nanoporous material studied. It should be noted that the more detailed computer simulations are inevitable, but the very small deviation of $\alpha$ from unity indicates that the nanoporous carbon has the narrow pore size distribution, which is in good agreement with the BET data (table 1 and figure 2).

At lower penetrability (at higher frequency), the penetration depth is smaller than the length of the pores, so that the ac signal detects only a part of the pore 

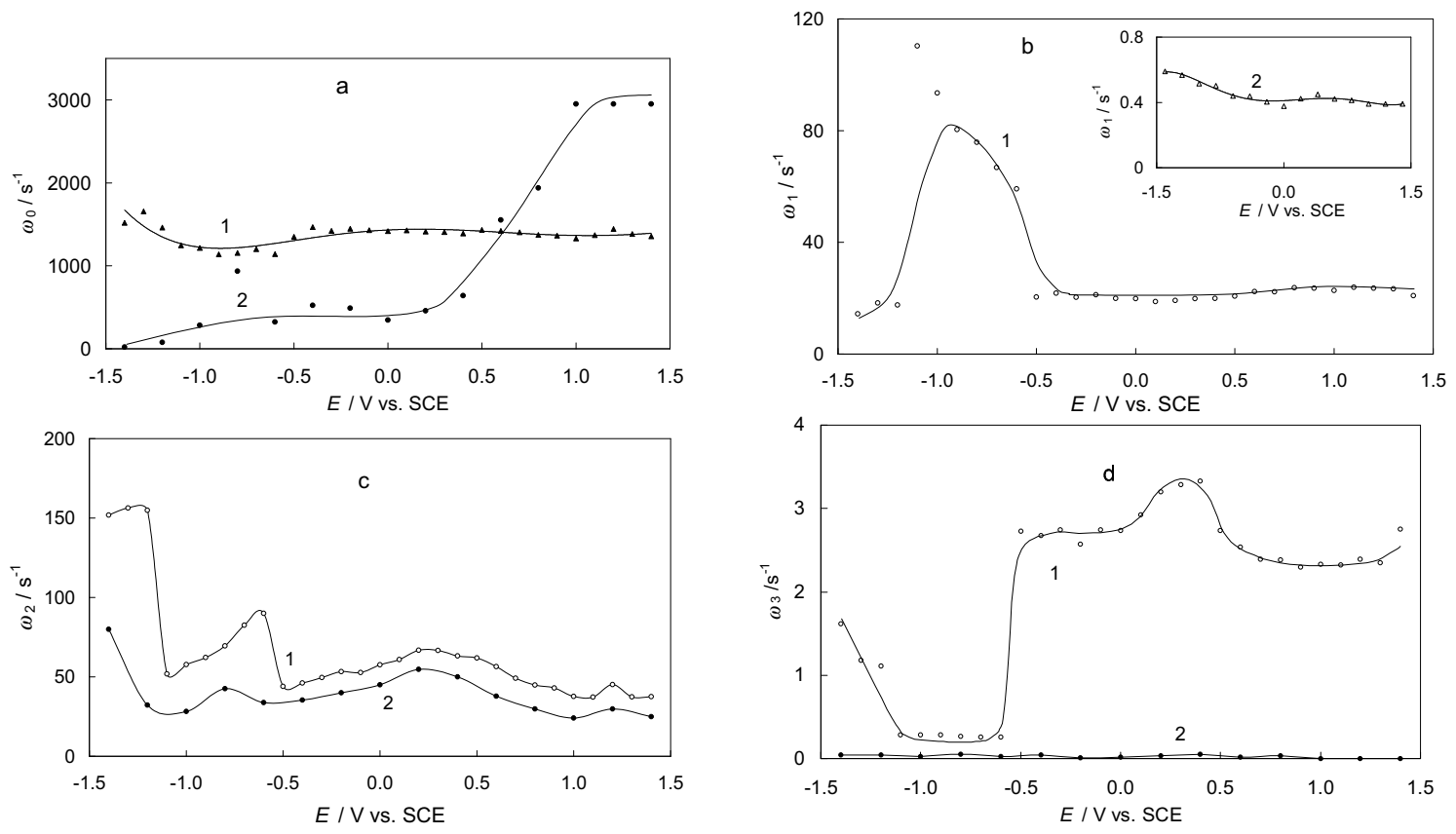

Figure 10. The dependence of the characteristic frequencies $\omega_{0}=k \sqrt{3}$ (a); $\omega_{1}$ (equations (6) and (6a)) (b); $\omega_{2}$ (equation (9)) (c); and $\omega_{3}$ (equation (10a)) (d) on the electrode potential for nanostructured carbon ID711 in $0.1 \mathrm{M}(1)$ and $1.5 \mathrm{M}$ (2) $\left(\mathrm{C}_{2} \mathrm{H}_{5}\right)_{4} \mathrm{NBF}_{4}+$ acetonitrile solutions.

volume, i.e. the nanopore surface. This is called the porous section of $Z^{\prime \prime}, Z^{\prime}$-plots, and the phase angle approaches -45 degrees in this region of ac frequency. In addition, there is a transition section between the porous and the planar sections in the $Z^{\prime \prime}, Z^{\prime}$-plots. At higher frequencies, there is a very well expressed and slightly depressed semicircle, with the depression angle $\beta$ only somewhat higher than zero ( $\beta=0$ corresponds to the purely charge transfer limited heterogeneous process, and $\beta=45^{\circ}$ corresponds to the diffusion limited stage) $[1,18,21,41]$. So, the very fast heterogeneous adsorption step (i.e. the partial charge transfer reaction) is probably possible in the case of the porous carbon $\left.\mid\left(\mathrm{C}_{2} \mathrm{H}_{5}\right)_{4} \mathrm{NBF}_{4}\right)+\mathrm{AN}$ interface. The values of effective pore volume $v_{\text {pore }}$, pore resistance $R_{\text {pore }}$ and the effective surface area of the nanoporous carbon electrode material, $S_{\mathrm{c}}$, obtained according to the models [18-25,32], are given in table 2 . As it can be seen in table 2 , the values of $v_{\text {pore }}$ and $S_{\mathrm{c}}$ decrease and $R_{\text {pore }}$ increase with the dilution of the electrolyte. Comparison of the effective surface area of the nanoporous carbon electrode with the values of nano-(micro-) pore area established by BET method shows that the surface of the very small nanopores does not contribute to the double layer capacitance.

The data in figures 8 and 10 indicate that the polarization propagates like diffusion (parameter $\omega_{0}=k \sqrt{3}$ ) through the electrode of finite thickness (related to $\omega_{1}$, equation (6a)), and that at any point, $x$, the finite diffusion, related to $\omega_{2}$ and $\omega_{3}$ (equations (9) and (10a)), results in a further time delay. The values of characteristic frequencies $\omega_{0}, \omega_{1}, \omega_{2}$ and $\omega_{3}$, obtained according to equations (6), (6a), (9) and 
(10b) by the simulation program [42], are given in figure 10. According to the results of the data of non-linear regression analysis [42], the chi-squared function $\left(\chi^{2}\right)$ has the usual values $\left(\chi^{2} \leqslant 3 \cdot 10^{-3}\right)$ for the electrochemistry when the complicated materials and systems are studied. The errors of individual parameters indicate a good agreement with the Paasch et al. model I. Therefore, the two parallel conduction paths in the solid and in the liquid phases are interconnected by the double layer capacitance in parallel with the complex admittance of the hindered charge transfer reaction (the equivalent circuit in the inset of figure 8).

Additionally, the Paasch et al. model II $[19,40]$ was tested, where the polarization field $E(\kappa, \omega)$, responsible for the ctr reaction, is not restricted to the volume average of the polarization at the interface but it can be extended into the solid phase. The results of the non-linear regression analysis demonstrate the noticeably higher deviation of the calculated $Z^{\prime \prime}, Z^{\prime}$-curves from the experimental data for this model than that for Paasch et al. model I, and therefore these data will not be discussed more in detail in this paper. According to our simulations, $\omega_{2} ; \omega_{3} \ll \omega_{0}$, and then the relative magnitudes of $\omega_{1}, \omega_{2}$ and $\omega_{3}$ determine the low-frequency behaviour of the $Z^{\prime \prime}, Z^{\prime}$-plots (figure 10). At very low frequency $f \leqslant 0.2 \mathrm{~Hz}$, there is a transition to a pure capacitive behaviour, since both the field diffusion and the species diffusion are finite. In the region of frequencies $0.2<f<10 \mathrm{~Hz}$, the slope equal to $\pi / 4$ for $Z^{\prime \prime}, Z^{\prime}$-plot was observed around $\omega_{2}$, where the diffusion of species dominates in the solution phase.

According to the data in figure 8, the shape of the complex plots depends on the concentration of the electrolyte, as well as on the electrode potential. The dependence of the $Z^{\prime \prime}, Z^{\prime}$-plots on the electrolyte concentration is caused mainly by the interplay of frequencies $\omega_{0}, \omega_{1}, \omega_{2}$ and $\omega_{3}$ and their dependence on $c_{\mathrm{el}}$. Thus, the characteristic frequencies depend noticeably on the nature and structure of the ions adsorbed at the nanoporous carbon electrode. At $E \ll E_{\sigma=0}$, there are mainly physically adsorbed $\left(\mathrm{C}_{2} \mathrm{H}_{5}\right)_{4} \mathrm{~N}^{+}$cations in the region of the inner layer but, at $E \gg E_{\sigma=0}$, the weak specific adsorption of anions is possible. Between the $\left(\mathrm{C}_{2} \mathrm{H}_{5}\right)_{4} \mathrm{~N}^{+}$cations, the van der Waals attractive interaction prevails, but there is repulsive interaction between weakly specifically adsorbed $\mathrm{BF}_{4}^{-}$anions. At higher frequencies $(f \geqslant 40 \mathrm{~Hz}$ $(0.1 \mathrm{M})$ and $f \geqslant 200 \mathrm{~Hz}(1.5 \mathrm{M}))$, the shape of the impedance spectra is determined mainly by the ratio of the $\omega_{0}$ and $\omega_{1}$ values, i.e. without regard to the diffusion in the pores [19].

\section{Conclusions}

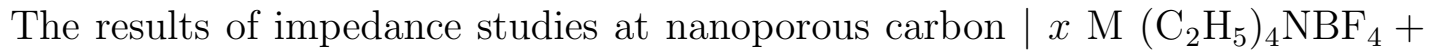
acetonitrile interface indicate that the series capacitance, series resistance, phase angle and other parameters depend noticeably on the concentration of electrolyte as well as on the electrode potential. It was found that the pore resistance, i.e. internal distribution of the electrode resistance rises noticeably with the dilution of the electrolyte solution. For the dilute electrolyte solutions, a very well expressed differential capacitance minima in the series capacitance-potential curves have been 
observed with the potential of the capacitance minimum, $E_{\min }$, dependent slightly on $c_{\mathrm{el}}$ and on the direction of potential scan if $c_{\mathrm{el}} \geqslant 0.01 \mathrm{M}$ and $\nu \geqslant 1 \mathrm{mV} / \mathrm{s}$. At $c_{\mathrm{el}} \leqslant 0.007 \mathrm{M}$, the values of $E_{\min }$ are practically independent of $\nu(\nu \leqslant 2 \mathrm{mV} / \mathrm{s})$ as well as of $c_{\mathrm{el}}$. Thus, to a first approximation, this potential value corresponds to the zero charge potential for the nanoporous carbon $\mid x \mathrm{M}\left(\mathrm{C}_{2} \mathrm{H}_{5}\right)_{4} \mathrm{NBF}_{4}+$ acetonitrile interface. Analysis of complex plane plots shows that the nanoporous carbon $\mid x \mathrm{M}$ $\left(\mathrm{C}_{2} \mathrm{H}_{5}\right)_{4} \mathrm{NBF}_{4}+$ acetonitrile interface can be simulated by the equivalent circuit, in which the two parallel conduction parts in the solid and liquid phases are interconnected by the double layer capacitance in parallel with the complex admittance of hindered reaction of the charge transfer process [21]. The values of the characteristic frequency depend on the electrolyte concentration and on the electrode potential, i.e. on the effective Debye screening length $[10,11,16,40]$ as well as on the nature and structure of ions adsorbed at the surface of nanoporous carbon electrode.

\section{Acknowledgements}

This work was supported in part by the Estonian Science Foundation under Project No. 4568.

\section{References}

1. Conway B.E. Electrochemical Supercapacitors. Scientific Fundamentals and Technological Applications. New York, Kluwer Academic/Plenum Publishers, 1999.

2. Randin J.B., Yeager E.B. // J. Electroanal. Chem., 1972, vol. 38, p. 257.

3. Salitra G., Soffer A., Eliad L., Cohen Y., Aurbach D. // J. Electrochem. Soc., 2000, vol. 146 , p. 2486.

4. Amokrane S., Badiali J.P. // J. Electroanal. Chem., 1989, vol. 266, p. 21.

5. Amokrane S., Badiali J.P. - In: J. O'M.Bockris, B.E.Conway and R.E.White (Eds.), Modern Aspects of Electrochemistry. Vol. 22. New York, Plenum Press, 1991, p. 1.

6. Lust E., Jänes A., Lust K., Väärtnõu M. // Electrochim. Acta, 1997, vol. 42, p. 771.

7. Emets V.V., Damaskin B.B., Kazarinov V.E. // Elektrokhimiya, 1995, vol. 31, p. 787.

8. Bruyant A., Smith D.P.E., Quante C.F. // Appl. Phys. Lett., 1986, vol. 48, p. 832.

9. Binning C., Smith D.P.E. // Rev. Sci. Instrum., 1986, vol. 57, p. 1688.

10. Daikin L.I., Kornyshev A.A, Urbakh M. // Phys. Rev. E, 1996, vol. 53, p. 6192.

11. Daikin L.I., Kornyshev A.A, Urbakh M. // J. Chem. Phys., 1998, vol. 108, p. 2853.

12. Trasatti S., Lust E. - In: R.E.White, B.E.Conway and J.O'M.Bockris (Eds.), Modern Aspects of Electrochemistry. Vol. 33. New York and London, Kluwer Academic/Plenum Publishers, 1999, p. 1.

13. Pecina O., Badiali J.P. // Phys. Rev. E, 1998, vol. 58, p. 6041.

14. Pecina O., Badiali J.P. // Phys. Rev. E, 1999, vol. 60, p. 4431.

15. Pecina O., Badiali J.P. // J. Electroanal. Chem., 1999, vol. 475, p. 46.

16. Lust E., Jänes A., Sammelselg V., Miidla P., Lust K. // Electrochim. Acta, 1998, vol. 44 , p. 373.

17. Jarzabek G., Borkovska Z. // Electrochim. Acta, 1997, vol. 42, p. 2915.

18. Macdonald J.R. Impedance Spectroscopy. New York, Wiley, 1987. 
19. Roušar I., Micka K., Kimla A. Electrochemical Engineering. Vol. 2. Amsterdam, Elsevier, 1986.

20. de Levie R. // J. Electroanal. Chem., 1990, vol. 281, p. 1.

21. Paasch G., Micka K., Gersdorf P. // Electrochim. Acta, 1993, vol. 38, p. 2653.

22. de Levie R. // Electrochim. Acta, 1963, vol. 8, p. 751.

23. de Levie R. // Electrochim. Acta, 1964, vol. 9, p. 1231.

24. Keiser H., Beccu K.D., Gutjahr M.A. // Electrochim. Acta, 1976, vol. 21, p. 539.

25. Keddam M., Rakomoto C., Takenouti H. // J. Applied Electrochem., 1984, vol. 14, p. 437.

26. Frumkin A.N., Melik-Gaikazyan V.I. // Dokl. akad. nauk SSSR, 1951, vol. 77, p. 855.

27. Lorenz W. // Z. Elektrochem., 1958, vol. 62, p. 192.

28. Armstrong R.P., Rice W.P., Thrisk H.R. // J. Electroanal. Chem., 1968, vol. 16, p. 517.

29. Rammelt U., Reinhard G., Rammelt K. // J. Electroanal. Chem., 1980, vol. 180, p. 327.

30. Paasch G., Schwarzenberg M., Jobst K., Sawtchenko L. // Mat. Sci. Forum, 1990, vol. $62-64$, p. 455.

31. Schneider W. // J. Phys. Chem., 1975, vol. 79, p. 127.

32. Micka K., Svatá M. // J. Power Sources, 1978, vol. 2, p. 167.

33. Izotov V.Y., Strizhakova N.G., Kozachkov S.G., Danilin V.V., Mironova A.A., Maletin Y.A., Lust E., Arulepp M., Jänes A., Nurk G., Perman L. Modeling the charge-discharge processes in porous electrodes - the way to double-layer capacitor optimization. // J. Power Sources (in press).

34. Arulepp M., Janes A., Nurk G., Permann L., Nigu P., Lust E. Electrochemical properties of skeleton carbon materials with large surface area and controlled pore size. In: Abstracts of 51st Annual ISE Meeting, Warsaw, 2000, s-8, p. 946.

35. Maletin Y.A., Strizhakova N.G., Izotov V.Y., Kozachkov S.G., Mironova A.A., Danilin V.V. - In: V.Barsukov and F.Beck (Eds.), New Promising Electrochemical Systems for Rechargable Batteries. Kluwer Academic Publishers, 1996, p. 363.

36. Maletin Y.A., Strizhakova N.G., Izotov V.Y., Kozachkov S.G., Mironova A.A., Danilin V.V., Ekström T. - In: Proc. 7th Sem. on Double Layer Capacitors and Similar Energy Storage Devices, Deerfield Beach Florida, USA.

37. Nurk G., Jänes A., Arulepp M., Nigu P., Permann L., Lust E. - In: Abstracts of Joint Int. Meeting of ISE and ECS, San Francisco, 2001, Abstr. No. 1006.

38. Gregg S.J., Sing K.S.W. Adsorption, Surface Area and Porosity. London, Academic Press, 1982.

39. Pell W.G., Conway B.E., Marincic N. // J. Electroanal. Chem., 2000, vol. 491, p. 9.

40. Lust E., Jänes A., Sammelselg V., Miidla P. // Electrochimica Acta, 2000, vol. 46, p. 185.

41. Song H.-K., Jung Y.-H., Lee K.-H., Dao L.H. // Electrochimica Acta, 1999, vol. 44, p. 3513.

42. Macdonald J.R. ZPlot for Windows (Version 2.2) Fitting Program, LEVM 6.0. 


\title{
Електрохімічні властивості нанопористих вуглецевих електродів
}

\author{
Е.Луст ${ }^{1,2}$, Г.Нурк ${ }^{1,2}$, А.Яанес ${ }^{1,2}$, М.Арулепп ${ }^{1,2}$, \\ Л.Перманн ${ }^{2}$, П.Нігу ${ }^{2}$, П.Мйоллер ${ }^{2}$ \\ 1 Інститут фізичної хімії, Університет м. Тарту \\ вул. Якобі 2, 51014 Тарту, Естонія \\ 2 тзОВ “Тарту Текнолоджіз”, вул. Рія 185, 51014 Тарту, Естонія
}

Отримано 5 жовтня 2001 р., в остаточному вигляді - 28 грудня $2001 \mathrm{p}$.

Методами циклічної вольтаметрії та імпедансної спектроскопії були досліджені подвійний електричний шар та електрохімічні характеристики міжфазної області вуглець | $\left(\mathrm{C}_{2} \mathrm{H}_{5}\right)_{4} \mathrm{NBF}_{4}+$ ацетонітрил. Були встановлені значення потенціалу нульового заряду (0.23 В відносно $\mathrm{SEE} \mathrm{в} \mathrm{H}_{2} \mathrm{O}$ ) область ідеальної поляризованості та інші характеристики. Аналіз графіків в комплексній площині показав, що лімфазна область вуглець $\mid x \mathrm{M}\left(\mathrm{C}_{2} \mathrm{H}_{5}\right)_{4} \mathrm{NBF}_{4}+$ ацетонітрил може бути змодельована еквівалентним колом, в якому дві паралельні провідні частини в твердій та рідкій фазі є зв'язані ємністю подвійного шару паралельно з комплексною повною провідністю зворотньої реакції процесу переносу заряду. Значення характеристичної частоти залежить від концентрації електроліту та потенціалу електрода, тобто природи іонів адсорбованих на поверхні нанопористого вуглецевого електроду.

Ключові слова: подвійний електричний шар, нанопористий вуглець, потенціал нульового заряду, неводний розчин електроліту

PACS: 68.08.-p, 68.08.De 
